\title{
Interaction of Carbon Dots from Grilled Spanish Mackerel with Human Serum Albumin, $\gamma$-Globulin and Fibrinogen
}

\author{
Guoxin Cui ${ }^{1,2,3}$, Yukun Song ${ }^{1,2,3}$, Kangjing Liu ${ }^{1,2,3}$ and Mingqian Tan 1,2,3,* \\ 1 Academy of Food Interdisciplinary Science, School of Food Science and Technology, \\ Dalian Polytechnic University, Dalian 116034, China; cuiguoxin89@163.com (G.C.); \\ songyukun@126.com (Y.S.); kangingliu123@163.com (K.L.) \\ 2 National Engineering Research Center of Seafood, Dalian Polytechnic University, Dalian 116034, China \\ 3 Collaborative Innovation Center of Seafood Deep Processing, Dalian Polytechnic University, \\ Dalian 116034, China \\ * Correspondence: mqtan@dlpu.edu.cn; Tel.: +86-411-86318657
}

check for updates

Citation: Cui, G.; Song, Y.; Liu, K.; Tan, M. Interaction of Carbon Dots from Grilled Spanish Mackerel with Human Serum Albumin, $\gamma$-Globulin and Fibrinogen. Foods 2021, 10, 2336. https://doi.org/10.3390/ foods10102336

Academic Editors: Federico Marini, Alessandra Biancolillo and Tanja Cirkovic Velickovic

Received: 25 August 2021

Accepted: 27 September 2021

Published: 30 September 2021

Publisher's Note: MDPI stays neutra with regard to jurisdictional claims in published maps and institutional affiliations.

Copyright: (C) 2021 by the authors. Licensee MDPI, Basel, Switzerland. This article is an open access article distributed under the terms and conditions of the Creative Commons Attribution (CC BY) license (https:/ creativecommons.org/licenses/by/ $4.0 /)$

\begin{abstract}
The potential biological effects of food-borne carbon dots (FCDs) generated during food heating procedures on human health has received great attention. The FCDs will be inevitably exposed to blood proteins along with our daily diet to produce unknown biological effects. In this study, the interaction between FCDs extracted from grilled Spanish mackerel and three main types of human plasma proteins including human serum albumin (HSA), human $\gamma$-globulin (HGG) and human fibrinogen (HF) was reported. It was found that the grilled Spanish mackerel FCDs could affect the morphology, size and surface electrical properties of the three proteins. The interaction between the FCDs and proteins had different effects on the secondary structure of the three proteins through a static mechanism. The tested HSA, HGG, and HF could adsorb FCDs to reach saturation state within $0.5 \mathrm{~min}$ after the adsorption happened. The binding affinity of the FCDs to the plasma proteins was sorted as follows: HF > HGG > HSA. The results of FCDs interacted with plasma proteins provided useful information in the assessment of the safety of FCDs in our daily diet.
\end{abstract}

Keywords: food-derived carbon dots; human serum albumin; $\gamma$-globulin; fibrinogen; interaction

\section{Introduction}

The impact of nanoparticles produced during food thermal processing on human health has received considered attention in the research field of food safety [1]. When nanoparticles enter the human body with food, they can inevitably interact with epithelial cells in the gastrointestinal tract, pass through the mucosa, enter the capillaries and distribute in organs and tissues [2]. In this process they will spontaneously adsorb proteins within the plasma, forming one or more layers of corona-like structures, which are generally called protein corona [3,4]. Grilled Spanish mackerel has become a favorite food for consumers because of its unique flavor and comprehensive nutrition. In previous research, food-derived carbon dots (FCDs) found in roast salmon and roast squid could enter the blood of mice after oral administration, and move to various organs such as heart, liver, lungs, and brain through bloodstream $[5,6]$. Therefore, the FCDs derived from grilled Spanish mackerel are inevitably exposed to plasma proteins after oral administration. However, the interaction of FCDs from grilled Spanish mackerel with various human plasma proteins is unknown. To this end, exploring the possible physiological interaction between FCDs and human plasma proteins is necessary to evaluate the safety of FCDs in baked food products.

It has been reported that the FCDs derived from grilled salmon could combine with digestive proteases (pepsin, trypsin) through the static interaction mechanism, change the secondary structure of the two proteases and inhibit enzyme activity [5]. Human serum albumin (HSA) could reduce the cytotoxicity of FCDs in grilled salmon, reduce the rate 
of apoptosis and slow down the disorders of glucose and lipid metabolism [7]. Moreover, the FCDs from roast beef could combine with HSA through electrostatic interaction or hydrophobic force, and were distributed in cell lysosomes. HSA also reduced the cytotoxicity of FCDs from beef, inhibited the swelling of the endoplasmic reticulum, caused the decrease of mitochondrial membrane potential, alleviated the generation of reactive oxygen species and slowed down the consumption of glutathione [8]. These findings provided useful information for the combination principle and cell safety of FCDs from different processed foods, which were helpful in the preliminary assessment of the safety of FCDs in our daily diet.

As we know, the blood transports nutrients and oxygen to and takes trash away from our body, which consists of more than 10,000 types of proteins $[9,10]$. The three most abundant proteins in human blood are albumin (55\%), globulin (38\%) and fibrinogen (7\%) [11]. Albumin can bind and transport water, cations, hormones, fatty acids and drugs, etc., and plays an important role in maintaining the osmotic pressure [12]. Globulins are classified into $\alpha 1$-globulin, $\alpha 2$-globulin, $\beta$-globulin and $\gamma$-globulin [13]. Among them, human $\gamma$-globulin (HGG) includes immunoglobulin, which plays a crucial part in the balance of the immune system and can temporarily enhance the immunity of patients by intravenous injection to treat certain immune diseases such as thrombocytopenic purpura $[14,15]$. Human fibrinogen $(\mathrm{HF})$ is a glycoprotein that can be converted into fibrin clots by thrombin during vascular injury. The increased content of fibrinogen is considered to be the cause of thrombosis and vascular injury [16]. All these three types of human protein have important functions during human physiological processes.

In this research, the plasma HSA, HGG and HF were selected as model proteins for the research of interaction with the FCDs from grilled Spanish mackerel (Scomberomorus commerson) due to their abundant content and important functions. The properties including morphology, size, molecular weight, and fluorescence properties of FCDs were studied, and then the influence of FCDs on fluorescence properties of HSA, HGG and HF was explored using the fluorescence, ultraviolet-visible (UV-Vis) spectroscopy and time-resolved fluorescence spectroscopy, etc, and the combination principle between FCDs and proteins were discussed. Fourier transform infrared spectroscopy (FTIR) and circular dichroism (CD) were used to analyze the influence of FCDs on the structure of the three types of proteins, and the structural changes of HSA, HGG and HF were proved through visualization. The adsorption capacity of FCDs and the three types of proteins were evaluated by the adsorption capacity experiment. The results of the interaction of FCDs with three human plasma proteins can provide useful information for evaluating the bio-effects of FCDs.

\section{Materials and Methods}

\subsection{Materials}

Fresh Spanish mackerel (Scomberomorus commerson) was obtained at the fish market in Ganjingzi District, Dalian, China. HSA (96-99\%) and PBS buffer solution (0.01 M) was purchased from Solarbio Technology (Beijing, China). HGG ( $\geq 99 \%)$ and HF (50-70\%, $\geq 80 \%$, clottable) were obtained from Sigma Aldrich (Shanghai, China). The bicinchoninic acid (BCA) protein assay kit was obtained from Beyotime Biotechnology (Shanghai, China). All other reagents applied in this research were analytically pure.

\subsection{Characterization Methods}

The molecular weight of FCDs was measured by matrix-assisted laser desorption/ionization time-of-flight mass spectrometer (MALDI-TOF-MS, Autoflex III, Bruker Daltonics, Bremen, Germany), using 2, 5-dihydroxybenzoic acid as a matrix. Transmission electron microscope (TEM) analysis was used a TEM (JEM-2100, JEOL, Tokyo, Japan) at a voltage of $200 \mathrm{kV}$. The ultrasonic particle size analyzer (DT1200) was used to measure the $\zeta$-potential of the samples. UV-Vis spectrophotometer (Lambda 35, PerkinElmer, Norwalk, CT, USA) was used to record the absorption spectra. The fluorescence spectra were performed 
with the F-2700 spectrofluorometer (Hitachi, Tokyo, Japan). The fluorescence lifetime was ascertained by an FLS980 spectrometer (Edinburgh Instruments, Edinburgh, UK). FTIR was conducted by a PerkinElmer spectrometer (Frontier, Norwalk, CT, USA). CD spectra were performed by a JASCO circular dichroism spectrometer (J-1500, Tokyo, Japan). Atomic force microscope (AFM) was used to measure the two/three-dimensional morphology and height of the samples (AFM-5500M, Hitachi, Tokyo, Japan). Unless otherwise stated, the sample concentration was $1 \mathrm{mg} / \mathrm{mL}$. All samples were dissolved in PBS buffer (0.01 M, $\mathrm{pH}$ 7.2-7.4). Before the test, the FCDs and protein mixture liquid was incubated in a water bath at $37^{\circ} \mathrm{C}$ for $10 \mathrm{~min}$.

\subsection{Preparation of FCDs}

The extraction method of FCDs was referred to our previous reporting [5]. Briefly, the fresh Spanish mackerel meat (1500 g, wet weight) was cut into pieces of $2 \mathrm{~cm} \times 1 \mathrm{~cm} \times 1 \mathrm{~cm}$, and grilled at $230{ }^{\circ} \mathrm{C}$ for $30 \mathrm{~min}$. The roasted flesh ( $405 \mathrm{~g}$ ) was added to ethanol in a ratio of 1:5 $(w / v)$, sonicated for $2 \mathrm{~h}$, and the mixture was filtered to remove impurities. The concentrated ethanol solution was then added to $150 \mathrm{~mL}$ of deionized water, and extracted with dichloromethane three times to remove the hydrophobic phase. The aqueous phase was centrifuged at 10,000 rpm for $10 \mathrm{~min}$ to remove the precipitate. The supernatant was concentrated by vacuum rotary evaporation, and purified by the D101 microporous resin column using deionized water as the eluent. The aqueous solution was concentrated by rotary evaporation again and purified through $0.22 \mu \mathrm{m}$ filter membrane and semi-preparative high-performance liquid chromatographic column C18 (20 mm $\times 300 \mathrm{~mm}, 10 \mu \mathrm{m})$ utilizing $10 \%$ methanol aqueous solution as mobile phase with the flow velocity of $18 \mathrm{~mL} / \mathrm{min}$. The fluorescent fractions were collected, concentrated and lyophilized to obtain FCDs powder (104 mg).

\subsection{Fluorescence Analysis}

The fluorescence data were calculated using the Stern-Volmer equation:

$$
\frac{F_{0}}{F}=1+k_{q} \tau_{0}[Q]=1+K_{s v}[Q]
$$

In this equation, $F_{0}$ and $F$ are the fluorescence intensity of the protein solution with FCDs not added or added, respectively, $K_{q}$ is the bimolecular quenching constant, $\tau_{0}$ is the average life expectancy of proteins, $K_{s v}$ is the dynamic quenching constant, and [Q] is the concentration of FCDs. Tryptophan in protein has the strongest fluorescence peak at the excitation wavelength of $280 \mathrm{~nm}$, the maximum excitation wavelength of tyrosine is $275 \mathrm{~nm}$, and phenylalanine also has the fluorescence peak at the excitation wavelength of $280 \mathrm{~nm}$ [17]. Therefore, the change of inherent fluorescence properties of protein can be monitored by selecting the excitation wavelength of $280 \mathrm{~nm}$.

Fluorescence lifetime was measured according to our previous method using an FLS980 spectrometer (Edinburgh Instruments, Edinburgh, UK) [18].

\subsection{Adsorption Measurement}

A total of $5 \mathrm{~mL}$ FCDs solution $(2.0 \mathrm{mg} / \mathrm{mL})$ was mingled with $5 \mathrm{~mL}$ of HSA, HGG, and HF $(0.5 \mathrm{mg} / \mathrm{mL})$, respectively. The solution had been preheated and incubated in a $37^{\circ} \mathrm{C}$ water bath. The reaction solution $(0.5 \mathrm{~mL})$ was collected at the corresponding time point at $0,0.5,1,2,3,4,5,10,20,30,40,50,60,120,180,240 \mathrm{~min}$, which was injected into $4{ }^{\circ} \mathrm{C}$ PBS buffer ( $\mathrm{pH} 7.2-7.4$ ) and diluted 5 times to stop the interaction. The proteinFCDs complex was centrifuged through an ultrafiltration centrifuge tube (50 k MWCO) at $3600 \mathrm{rpm}, 4^{\circ} \mathrm{C}$ for $10 \mathrm{~min}$, to remove the free FCDs. The ultrafiltrate was collected and tested with $10 \mu \mathrm{L}$ of Bradford solution to check whether there was protein leakage in the filtrate. The concentration of FCDs was measured at the wavelength of $562 \mathrm{~nm}$ using the BCA kit (Solarbio). The concentration of FCDs was quantified by standard curve, and the 
concentration of FCDs adsorbed by proteins was calculated by the difference between the initial concentration that was added and measured in the ultrafiltrate.

\section{Results and Discussion}

\subsection{Characterization of FCDs}

The FCDs, fluorescent carbon-rich nanoparticles with good water solubility, were extracted from grilled Spanish mackerel and appeared as a brown powder (Figure 1a). The aqueous solution of FCDs emitted blue fluorescence under $365 \mathrm{~nm}$ ultraviolet light and the fluorescence intensity increased with the increase of the concentration (Figure 1b). The analysis of MALDI-TOF-MS showed a main peak at $761.204 \mathrm{~m} / \mathrm{z}$ (Figure 1c), which was composed of carbon-hydrogen-oxygen-nitrogen elements without exact molecular structures. In the subsequent computational process, 761.204 Da was used as the average molecular weight of FCDs. TEM image showed that the FCDs were nearly spherical with uniform size and good dispersion. The average diameter of FCDs was $2.94 \pm 0.03 \mathrm{~nm}$ (Figure 1d). Besides, the AFM images clearly showed that the height of FCDs in grilled Spanish mackerel was about 2-4 nm (Figure 1e), which further confirmed the TEM results. In another study, the height of FCDs in roast duck was $2-4 \mathrm{~nm}$, and as the roasting temperature increased from $200-300^{\circ} \mathrm{C}$, the height of FCDs became more uniform [6]. The height of FCDs in grilled squid was 2-6 nm, and it was speculated that the height of FCDs was comparable with the size of TEM [19]. The FCDs with an ultra-small size and high surface to area ratio may have great potential interaction with human blood proteins.

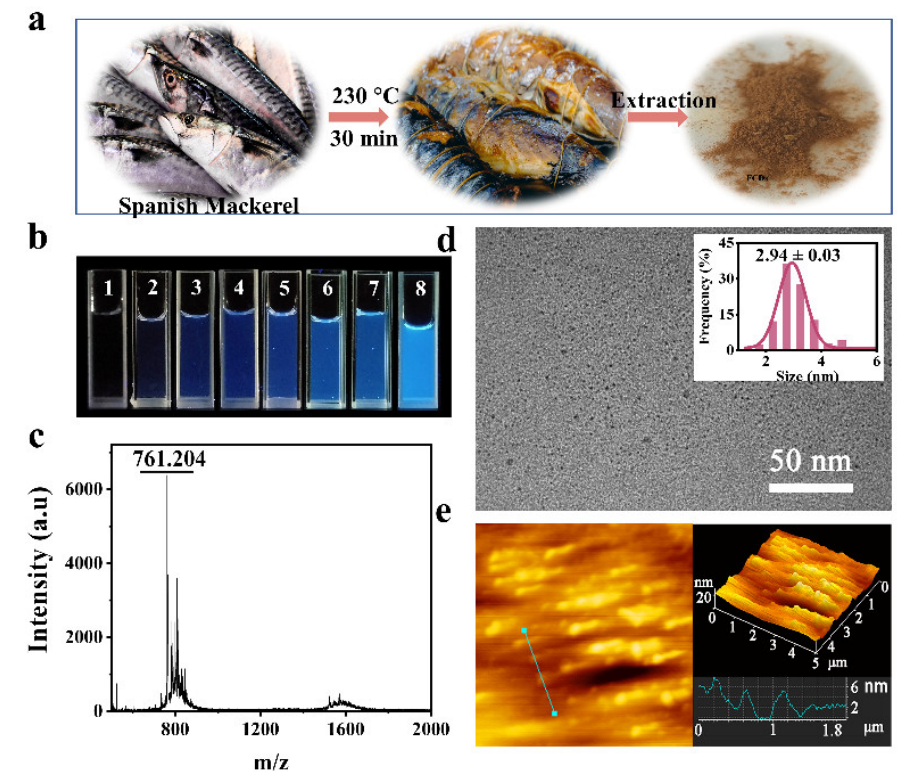

Figure 1. Characterization of FCDs. (a) Schematic diagram of FCDs derived from grilled Spanish mackerel at $230{ }^{\circ} \mathrm{C}$ for $30 \mathrm{~min}$. (b) FCDs aqueous solution under $365 \mathrm{~nm}$ ultraviolet light. The concentrations of FCDs in 1-8 solution were $0,2,4,6,8,10,12,24 \times 10^{-5} \mathrm{~mol} / \mathrm{L}$, respectively. (c) MALDI-TOF-MS spectrum of FCDs. (d) TEM image and the corresponding size analysis of FCDs $(n=180)$. (e) Two-dimensional (2D) and 3D AFM images of FCDs derived from grilled Spanish mackerel.

\subsection{Interaction between FCDs and Proteins}

To explore the interaction effects of FCDs with HSA, HGG, and HF, TEM was used to measure the size, dispersion and morphology of the three types of proteins after interaction with FCDs. The proteins, negatively stained with phosphotungstic acid, showed a nearly spherical morphology. In detail, the TEM image of HSA demonstrated that the HSA was well-dispersed and the average size was $17.68 \pm 0.05 \mathrm{~nm}$ (Figure 2a). This is similar to the HSA size determined by crystallographic methods at a resolution of $6.0 \AA ̊$ with unit cell 
size $\mathrm{a}=\mathrm{b}=186.5 \pm 0.5 \AA, \mathrm{c}=81.0 \pm 0.5 \AA$ [20]. The size also corresponds to the unit cell size determined at a resolution of $3.0 \AA, \mathrm{a}=\mathrm{b}=187.1 \AA, \mathrm{c}=80.5 \AA$ [21]. Actually, the shape of HSA was a heart-like asymmetric structure with equilateral triangle sides of $\sim 80 \AA$ [22]. The observed HSA image was probably the dimer or multimer of the single molecules in the PBS solution. After interacting with FCDs, the average size of HSA increased to $20.20 \pm 0.16 \mathrm{~nm}$ (Figure 2d), which corresponds to the sum of the sizes of FCDs and HSA, indicating that HSA and FCDs may adsorb each other and form the complex. The average size of HGG was $33.97 \pm 1.57 \mathrm{~nm}$ (Figure 2b). Kumakura et al. proposed that the size of HGG molecules was $100-200 \AA$, and the apparent volume would increase due to the entanglement of the molecules in the solution [23]. After interacting with FCDs, the size of HGG and FCDs complex increased to $42.51 \pm 1.10 \mathrm{~nm}$ (Figure 2e). Unlike HSA and HGG, the HF did not completely exist in its original form, and multimers formed by the horizontal end-to-end connections of particles can be observed (Figure 2c). The high heterogeneity of HF had been confirmed in the previous studies $[16,24,25]$. The high degree of heterogeneity is inseparable from the intermediates produced in the three steps of converting fibrinogen to fibrin. In the first step, fibrinogen releases fibrin peptides and forms fibrin monomers under the catalysis of thrombin. In the second step, fibrin monomers form fibrin polymers through non-covalent interactions. In the third step, the polymer aggregates to form the fibrin clot $[26,27]$. Several reports proved that the length of HF was around $45 \mathrm{~nm}[28,29]$, and the average particle size here was also $45.48 \pm 1.76 \mathrm{~nm}$ (Figure 2c). But fibrinogen is a slender bio-polymer, and the size of the particles here could correspond to the fibrinogen monomer of 41.0-43.5 nm (Figure 2c) [30]. After interacting with FCDs, the particle size of the HF slightly increased to $46.00 \pm 0.24 \mathrm{~nm}$, and the connection among the particles could not be found in the sample (Figure 2f). It is speculated that the FCDs probably prevent the non-covalent interaction between HF particles, so that the monomers could not be connected, and inhibited the formation of fibrin multimers. All the size increase of the HSA, HGG and HF after interaction with FCDs, indicated that the FCDs caused influence when they were dispersed in the aqueous solution of HSA, HGG and HF, respectively.
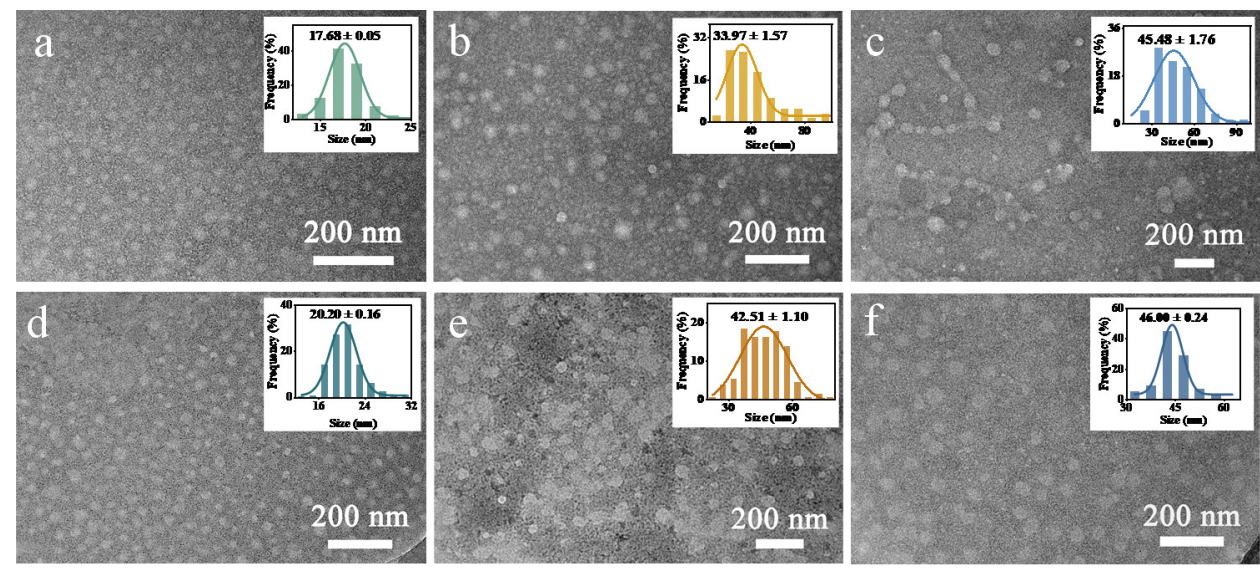

Figure 2. TEM pictures of (a) HSA, (b) HGG, (c) HF (d) HSA-FCDs, (e) HGG-FCDs, (f) HF-FCDs, and the corresponding size distributions measured in $0.01 \mathrm{M}$ PBS.

Then $\zeta$-potential was monitored to study the change of surface charge of HSA, HGG, HF in the presence of FCDs. The result showed that the average potential of FCDs was $-8.99 \mathrm{mV}$ (Figure 3a). After adding FCDs to the protein particles, the average potential of HSA dropped from -8.12 to $-9.75 \mathrm{mV}$, while the average potential of HGG was basically unchanged. The average potential of HF showed an opposite trend to that of HSA, rising from -10.27 to $-8.88 \mathrm{mV}$ (Figure 3a). One of the possible explanations for this phenomenon is that the FCDs may change the surface structure of HSA and HF during the formation of HSA-FCDs and HF-FCDs. It should be noted that $\zeta$-potential provided indicative information about colloidal stability, but the steric interaction between molecules also 
contributed to colloidal stability [31], which might also be used to explain the slight change in the $\zeta$-potential of HGG after interacting with FCDs. In addition, the HF showed an electrical neutralization phenomenon after adding FCDs, suggesting that the interaction between HF and FCDs was related to electrostatic characteristics.

a

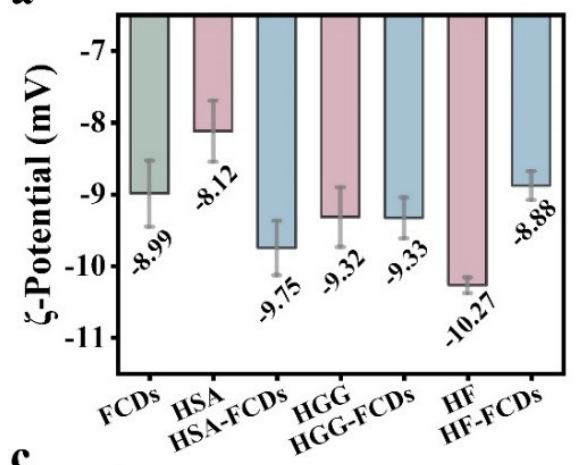

c

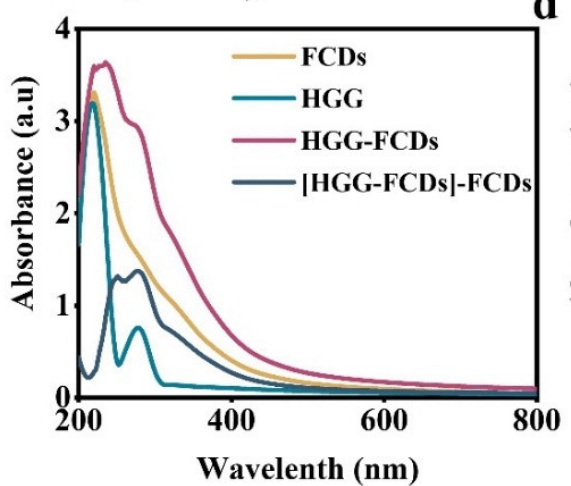

b
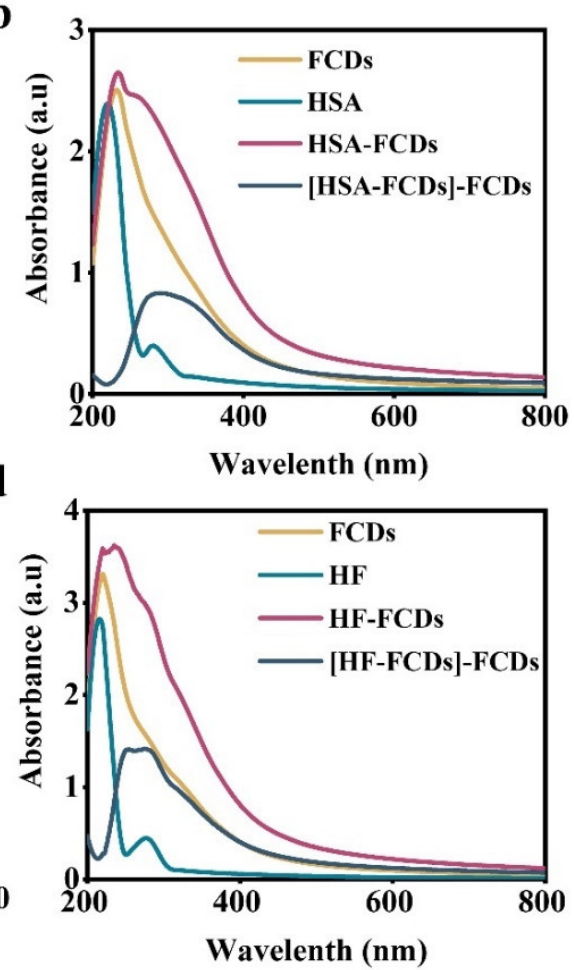

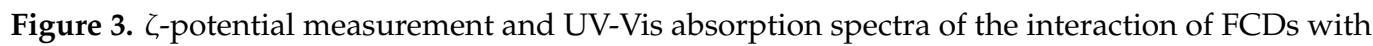
HSA, HGG and HF. (a) $\zeta$-potential. $n=6$. UV-Vis absorption spectra of (b) HSA, (c) HGG, and (d) HF.

Figure $3 b-d$ show the UV-Vis absorption spectra of FCDs, HSA, HGG and HF, respectively. The spectra of HSA, HSA-FCDs, and [HSA-FCDs]-FCDs were significantly different. After adding FCDs, the single peak of HSA red-shifted and the absorption intensity also increased. Similar results were also found for the HGG and HF. This indicated that the addition of FCDs affected the microenvironment of the three types of protein, and this indicated that the proteins and FCDs adsorbed to each other and formed the complex.

The fluorescence spectra change may provide in-depth information on the molecular interaction between FCDs and plasma proteins. As the concentration of FCDs increased, the fluorescence emission intensity of the proteins gradually decreased (Figure $4 \mathrm{a}-\mathrm{c}$ ). Meanwhile, the maximum emission wavelengths of the HGG spectra were red-shifted, suggesting that the FCDs had a more obvious effect on HGG fluorophores. This was probably due to the increase in the protonation level of the area around the fluorophore, resulting in the change of hydrophobic domain [32]. In the concentration of $0-12 \times 10^{-5} \mathrm{~mol} / \mathrm{L}$, the fluorescence results were in keeping with the Stern-Volmer equation with good linear relationships between the $F_{0} / F$ value and the FCDs concentration (Figure $4 \mathrm{~d}$ ). The calculated quenching rate constants $\mathrm{kq}$ from the Stern-Volmer equation were $k_{q}(\mathrm{HSA})=9.47$ $\times 10^{10} \mathrm{M}^{-1} \mathrm{~s}^{-1}, k_{q}(\mathrm{HGG})=7.77 \times 10^{10} \mathrm{M}^{-1} \mathrm{~s}^{-1}, k_{q}(\mathrm{HF})=5.46 \times 10^{10} \mathrm{M}^{-1} \mathrm{~s}^{-1}$, respectively. All these $k_{q}$ values were larger than the maximal diffusion rate constant of biomacromolecule $\left(2 \times 10^{10} \mathrm{M}^{-1} \mathrm{~s}^{-1}\right)$ [33]. This finding proved that FCDs combined with HSA, HGG and HF through a static quenching mechanism. Static quenching was arisen from the forming process of nonluminous ground state complexes [34], which inferred that the FCDs formed complexes with HSA, HGG, and HF. Rayleigh scattering is considered to be one of the interference factors in fluorescence spectrometry, and its peak resonates with the fluorescence peak. When the particle size is the same, the strength of the resonant scat- 
tering peak has been proved to be proportional to the concentration of nanoparticles [35]. Herein, increasing concentration of FCDs was found to quench the intrinsic fluorescence of proteins, without the negative effects of Rayleigh scattering. In addition, unlike dynamical quenching that only influences the excited state of the molecule, static quenching will lead to the change of the absorption spectra of the fluorophore, but does not affect the absorption spectra of the quenched substance [36]. This was demonstrated in the UV-Vis absorption spectra of Figure 3.
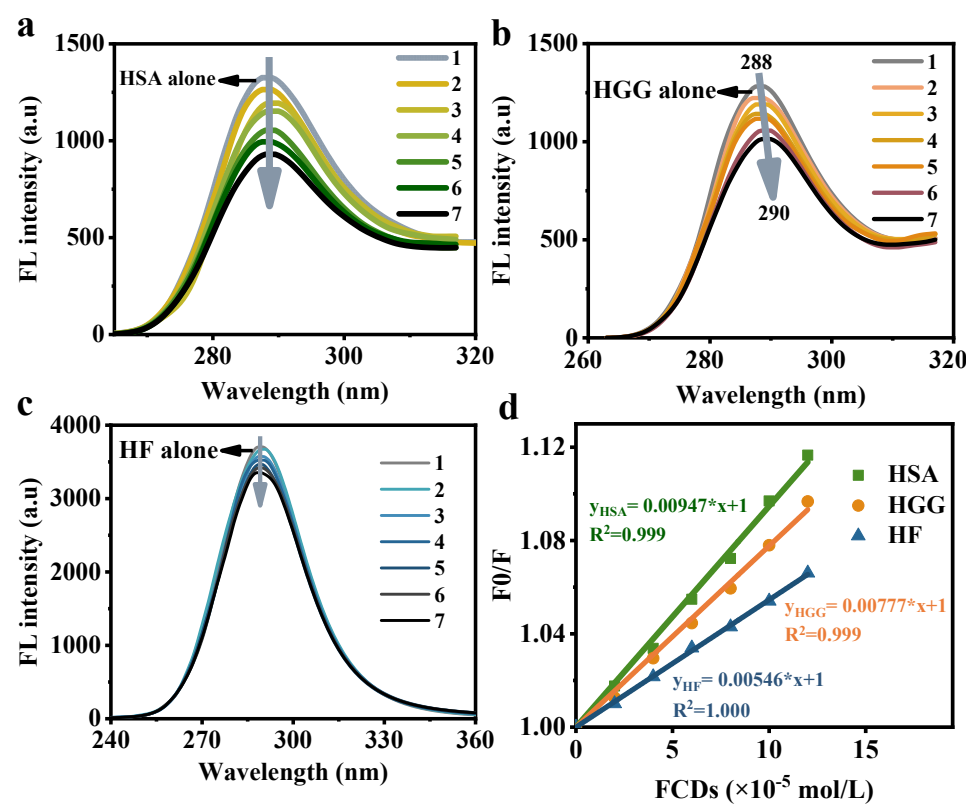

Figure 4. Fluorescence emission spectra of (a) HSA, (b) HGG, (c) HF in the existence of different concentrations of FCDs. (d) Stern-Volmer linear relationship curves of HSA, HGG, and HF quenched by FCDs at $298 \mathrm{~K}$. The excitation wavelengths were $280 \mathrm{~nm}$. The concentrations of HSA, HGG and $\mathrm{HF}$ in the solution were $1 \times 10^{-7} \mathrm{~mol} / \mathrm{L}$, and the concentrations of FCDs in the 1-7 curves were 0,2 , $4,6,8,10$ and $12 \times 10^{-5} \mathrm{~mol} / \mathrm{L}$, respectively.

Time-resolved fluorescence spectroscopy can verify the combination mechanism by analyzing the fluorescence lifetime of the nanoparticles before and after the interaction with plasma proteins. The fluorescence lifetimes of FCDs calculated by the multi-exponential equation changed from 7.719 to $7.622,7.476$ and $7.557 \mathrm{~ns}$ after interacting with HSA, HGG and HF, respectively (Figure 5a-d). The lifetimes were reduced by $1.26,3.15$ and $2.10 \%$, respectively, and the changes in fluorescence lifetime were much lower than the reported dynamic quenching degree of $31.17 \%[18,37]$. This further supported the static combination of the three proteins with FCDs.

Synchronous fluorescence spectroscopy can provide instruction about the biomolecular microenvironment around the protein or amino acid fluorophores. The feature information of tyrosine (Tyr) and tryptophan (Trp) can be monitored by inputting a fixed $\Delta \lambda$ value of 15 or $60 \mathrm{~nm}$ between the two monochromators [38,39]. With the concentration increase of FCDs, the synchronous fluorescence intensity of all amino acid residues of the three proteins decreased gradually. The maximum emission wavelength of HSA on the condition that $\Delta \lambda=15 \mathrm{~nm}$ was found a red-shift (Figure 6a), indicating that the hydrophobicity of Tyr residues decreased. The maximum emission wavelength under $\Delta \lambda=60 \mathrm{~nm}$ did not change (Figure 6b), indicating that there was little microenvironmental disturbance around Trp [5]. The change of maximum emission wavelengths of HGG and HF was not obvious under $\Delta \lambda=15 \mathrm{~nm}$ (Figure 6c,e), while the maximum emission shifted to longer wavelength slightly under $\Delta \lambda=60 \mathrm{~nm}$ (Figure $6 \mathrm{~d}, \mathrm{f})$, indicating that the residue hydrophilicity and chain extension of HGG and HF increased as well [40]. 

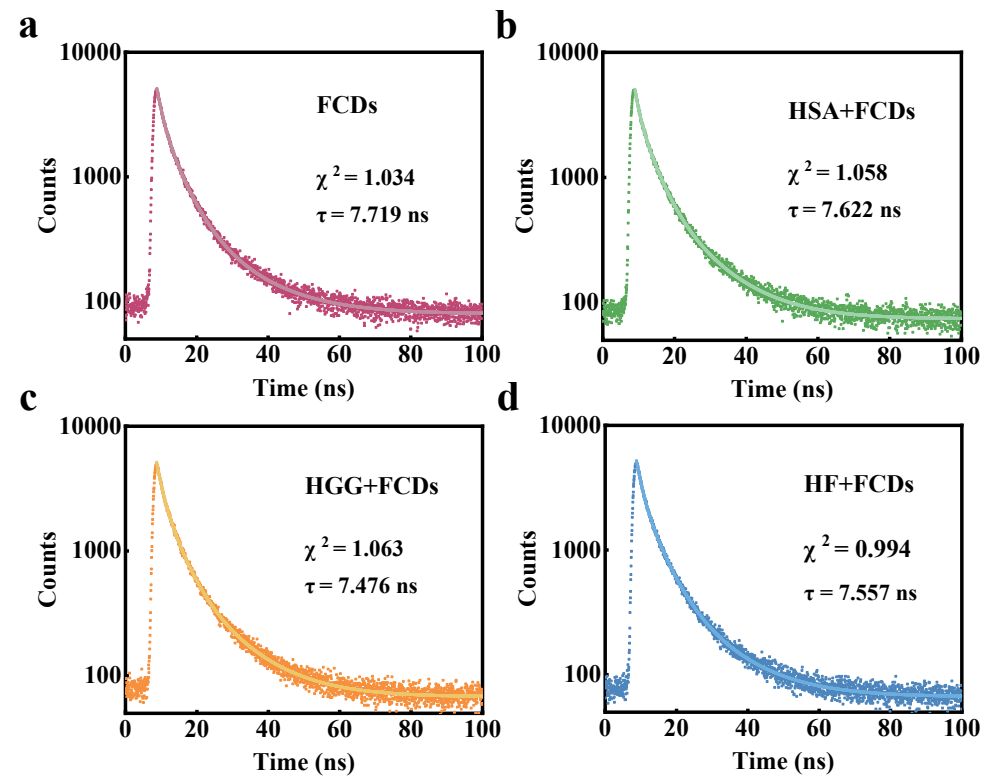

Figure 5. Fluorescence lifetime decay curves of (a) FCDs, and (b) FCDs-HSA, (c) FCDs-HGG and (d) FCDs-HF.
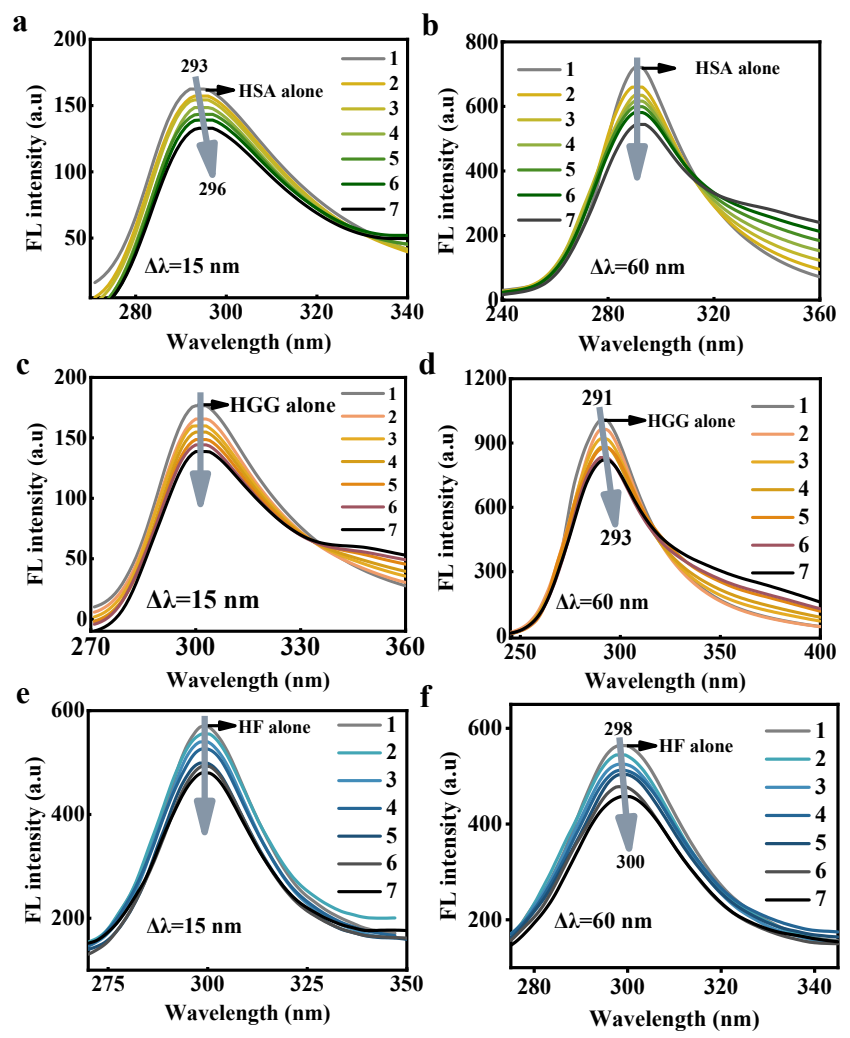

Figure 6. Synchronous fluorescence spectra of HSA, HGG and HF incubated with different concentrations of FCDs under $\Delta \lambda=15$ and $60 \mathrm{~nm}$. The excitation wavelength was $280 \mathrm{~nm}$. (a) HSA under $\Delta \lambda=15 \mathrm{~nm}$. (b) HSA under $\Delta \lambda=60 \mathrm{~nm}$. (c) HGG under $\Delta \lambda=15 \mathrm{~nm}$. (d) HGG under $\Delta \lambda=60 \mathrm{~nm}$. (e) HF under $\Delta \lambda=15 \mathrm{~nm}$. (f) HF under $\Delta \lambda=60 \mathrm{~nm}$. The concentrations of HSA, HGG and HF in the solution were $1 \times 10^{-7} \mathrm{~mol} / \mathrm{L}$, and the concentrations of FCDs in the $1-7$ curves were $0,2,4,6,8,10$ and $12 \times 10^{-5} \mathrm{~mol} / \mathrm{L}$, respectively. 


\subsection{Structural Analysis}

Next, the conformational change of the three proteins after the interaction with FCDs was analyzed with FTIR spectroscopy. The peaks of FCDs at $3308 \mathrm{~cm}^{-1}$ and $2927 \mathrm{~cm}^{-1}$ were attributed to the stretching vibration of $\mathrm{C}-\mathrm{OH}$ and $\mathrm{C}-\mathrm{H}$, respectively (Figure 7a) [41]. The amide I band in the range of $1600-1700 \mathrm{~cm}^{-1}$ corresponded to the $\mathrm{C}=\mathrm{O}$ tensile vibration, while the amide II band between 1500 and $1600 \mathrm{~cm}^{-1}$ was due to the N-H bending vibration [42]. The peaks at 1403 and $1063 \mathrm{~cm}^{-1}$ were related to C-N bonds and C-O-C bonds, respectively [6]. After the interaction of HSA with FCDs, the absorption peak of the amide I band was significantly enhanced, while the amide II band was weakened. This indicated that the secondary structure of HSA might be rearranged. After HGG interacted with FCDs, the absorption peak of amide I band was greatly enhanced (Figure $7 \mathrm{~b}$ ), suggesting that the interaction greatly affected the $\mathrm{C}=\mathrm{O}$ tensile vibration of HGG. After HF interacted with FCDs, the intensity and position of the amide band absorption peak were basically unchanged (Figure 7c). The FTIR spectra showed that the FCDs could affect the structure of the three types of proteins, thus prompting us to further explore the influence of FCDs on the structure of proteins.
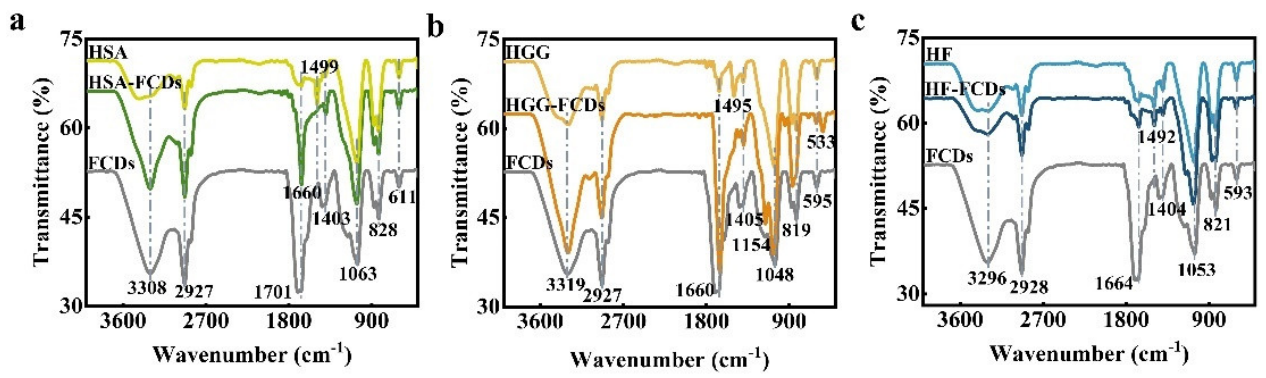

Figure 7. FTIR spectra of FCDs interacting with HSA, HGG, HF. (a) HSA. (b) HGG. (c) HF.

To further explore the effect of FCDs on the secondary conformation of the plasma proteins, $\mathrm{CD}$ spectroscopy was applied as a powerful tool to investigate the interaction of FCDs with plasma proteins by measuring the proportion of the four secondary structures of proteins in the total secondary structure. The proteins with different secondary structures have different absorption peaks and absorption intensities. For example, the $\alpha$-helix has a positive absorption band at $192 \mathrm{~nm}$, with two negative absorption bands at 222 and $208 \mathrm{~nm}$, respectively. The $\beta$-sheet has a negative absorption band at $216 \mathrm{~nm}$ and a positive absorption band around 195-198 nm. The percentage of protein secondary structures can be calculated based on the absorption intensity of particular secondary structure with the software. As shown in Figure 8, the CD spectra in the range of 190-260 nm showed that the proportion of $\alpha$-helix of natural HSA and HF were $45.0 \%$ and $42.2 \%$, respectively, which decreased to $25.3 \%$ and $21.1 \%$ when the concentration of FCDs increased from 0 to $1 \times 10^{-4} \mathrm{~mol} / \mathrm{L}$. The $\alpha$-helix of natural HGG decreased from $41.3 \%$ to $3.7 \%$ when the concentration of FCDs increased from 0 to $1 \times 10^{-4} \mathrm{~mol} / \mathrm{L}$. The ratios of the secondary conformation of the three proteins were listed in Table 1. The $\beta$-sheet of HSA remained unchanged, while increased significantly for the HGG and HF with the increase of the FCDs concentration. The $\beta$-turn showed an increasing trend from $10.8 \%$ to $24.2 \%$ for HSA, while it completely disappeared for HGG when the concentration of FCDs increased from 0 to $1 \times 10^{-4} \mathrm{~mol} / \mathrm{L}$. In addition, $\beta$-sheet appeared as the FCDs increased to $6 \times 10^{-5} \mathrm{~mol} / \mathrm{L}$ for HF. So the secondary structure of HGG and HF was affected by the FCDs, and there might be the unfolding of peptides, and even the destruction of the protein hydrogen bond network leading to the distortion of $\beta$-sheet [43]. With the increase of the concentration of FCDs added, the proportion of random coil of the three types of proteins showed an increasing trend, which also proved that FCDs caused the structure change of the proteins. 

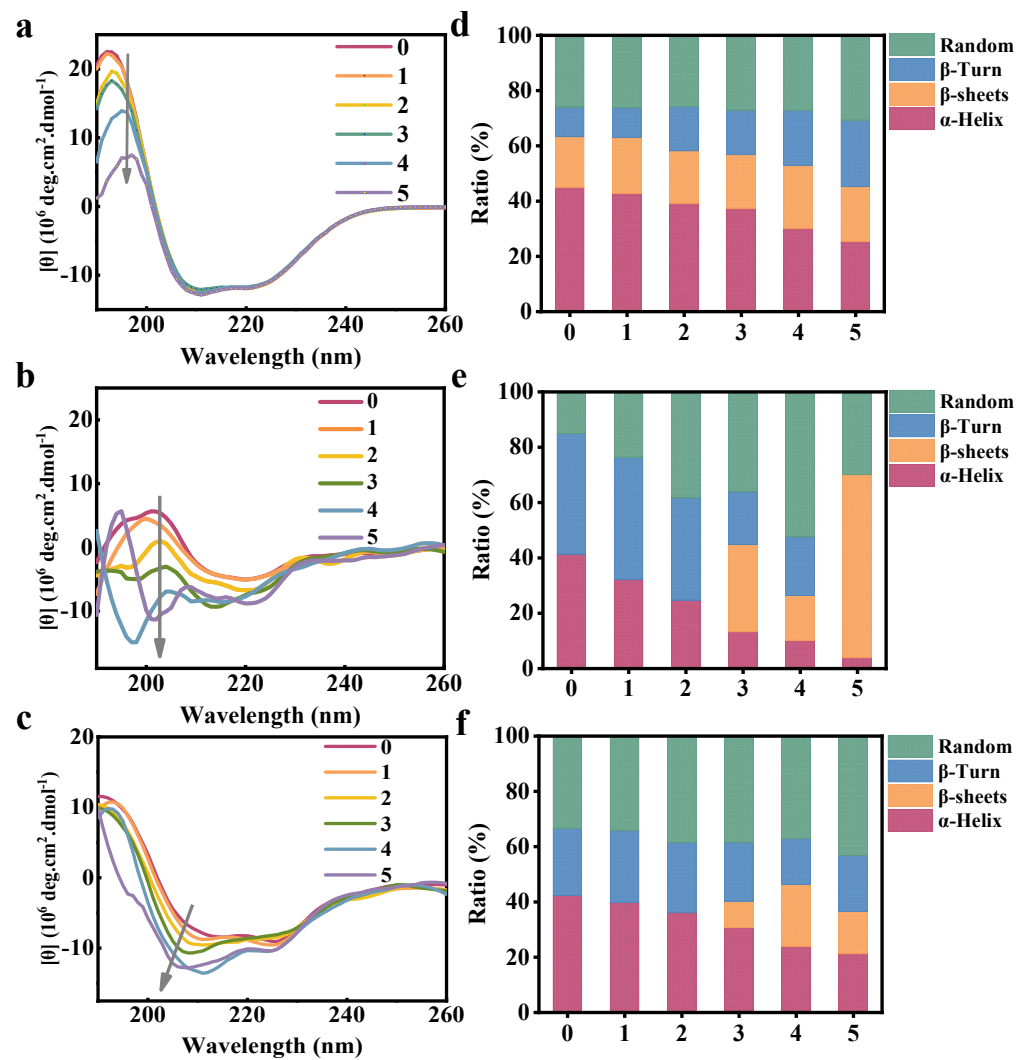

Figure 8. CD spectra of FCDs interacting with HSA, HGG, HF and the corresponding secondary structure ratio analysis. CD spectra of (a) HSA, (b) HGG, and (c) HF. Secondary structure ratio analysis of (d) HSA, (e) HGG, and (f) HF. The concentrations of HSA, HGG and HF in the solution were $1 \times 10^{-7} \mathrm{~mol} / \mathrm{L}$, and the concentrations of FCDs in the $0-5$ curves were $0,2,4,6,8$ and $10 \times 10^{-5} \mathrm{~mol} / \mathrm{L}$, respectively.

Table 1. Changes in the secondary conformation of HSA, HGG, HF in the presence of FCDs.

\begin{tabular}{cccccccc}
\hline Ratio (\%) & FCDs (mmol/L) & $\mathbf{0 . 0 0}$ & $\mathbf{0 . 0 2}$ & $\mathbf{0 . 0 4}$ & $\mathbf{0 . 0 6}$ & $\mathbf{0 . 0 8}$ & $\mathbf{0 . 1 0}$ \\
\hline \multirow{4}{*}{ HSA } & $\alpha$-Helix & 45.0 & 42.6 & 39.1 & 37.3 & 29.9 & 25.3 \\
& $\beta$-sheet & 18.2 & 20.4 & 19.0 & 19.4 & 23.0 & 19.8 \\
& $\beta$-Turn & 10.8 & 10.7 & 16.0 & 16.2 & 19.8 & 24.2 \\
& Random & 26.0 & 26.2 & 26.0 & 27.1 & 27.2 & 30.7 \\
\hline \multirow{4}{*}{ HGG } & $\alpha$-Helix & 41.3 & 32.0 & 24.6 & 13.1 & 10.1 & 3.7 \\
& $\beta$-sheet & 0.0 & 0.0 & 0.0 & 31.6 & 16.2 & 66.3 \\
& $\beta$-Turn & 43.6 & 44.3 & 37.0 & 19.1 & 21.2 & 0.0 \\
& Random & 15.1 & 23.8 & 38.3 & 36.2 & 52.5 & 30.0 \\
\hline \multirow{4}{*}{ HF } & $\alpha$-Helix & 42.2 & 39.7 & 36.0 & 30.6 & 23.9 & 21.1 \\
& $\beta$-sheet & 0.0 & 0.0 & 0.0 & 9.6 & 22.3 & 15.4 \\
& $\beta$-Turn & 24.4 & 26.0 & 25.4 & 21.4 & 16.6 & 20.2 \\
& Random & 33.4 & 34.3 & 38.6 & 38.3 & 37.2 & 43.3 \\
\hline
\end{tabular}

More detailed information on the surface morphology and structure of the protein was obtained by AFM imaging [44]. Figure 9 shows the AFM images of the HSA, HGG and HF before and after interaction with FCDs. The AFM image of HSA showed the nanoparticles with a height of 4-8 $\mathrm{nm}$ (Figure 9a), which corresponded to the reported oblate ellipsoid with a heart-shaped structure having a side length of $80 \AA$ described by crystallographic methods at a resolution of $2.8 \AA$ [22,45]. After adding FCDs, the dispersion of HSA-FCDs changed to cluster, and the height increased to $10-15 \mathrm{~nm}$ (Figure 9d). This inferred that the HSA and FCDs adsorbed to each other and formed the complex. The 
AFM image of HGG also showed a spherical shape in the plane diagram. The difference was that the surface center of particles was hollow and uneven, with an average height of 3-6 nm (Figure 9b). Its height can correspond to the HGG measured by the ellipsometer, with an average height of $45 \AA$ [46], and also close to the height of immunoglobulin G $(4 \mathrm{~nm})$ [47]. After interacting with FCDs, the height of HGG increased to 9-11 nm, and the obvious adhesion phenomenon was observed (Figure 9e). In addition, the morphology of HF was a slender strip with multiple nodules (Figure 9c), which corresponded exactly to the three-nodular structure described in previous studies [48,49]. The height of HF was 5-15 $\mathrm{nm}$ (Figure 9c), the dense particles made the substrate height uneven, which limited the accurate analysis. Evans-Nguyen et al. described the height of the HF monolayer as $5.5 \pm 2.2 \mathrm{~nm}$ [50]. Kollman et al. determined the minimum three-dimensional crystal size of HF at a resolution of approximately $3.3 \AA$ to be $94.87 \AA$ [51]. Fowler \& Erickson described the two outer nodules of HF with a diameter of 6-7 nm and the middle nodule with a diameter of 4-5 nm [52]. The height of HF in the range of 5-15 nm was consistent with the results that mentioned above. After interacting with FCDs, the morphology of HF changed, the nodular structure was changed, and the height increased to $20-30 \mathrm{~nm}$ (Figure 9f). This revealed that HF and FCDs adsorbed each other to form nanocomplex. The AFM results directly proved that the FCDs decreased the uniformity of the HGG, and changed the surface structure of HSA and HF.
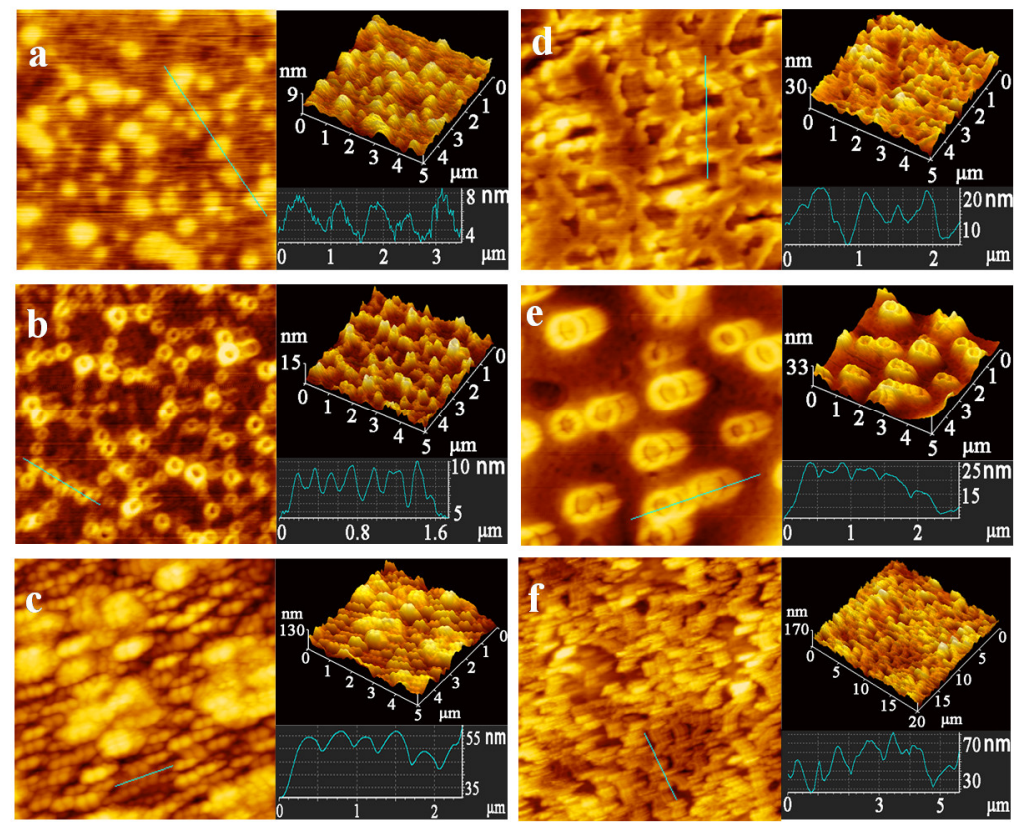

Figure 9. AFM 2D and 3D images of (a) HSA, (b) HGG, (c) HF, (d) FCDs-HSA, (e) FCDs-HGG, (f) FCDs-HF, and the corresponding size and height analysis.

\subsection{Adsorption Capacity and Ratio}

In addition to the effects of FCDs on the structure of the three types of protein, HSA, HGG and HF, the adsorption capacity and binding ratio between proteins and FCDs were also studied. The traditional BCA protein adsorption capacity determination method requires the separation of the complex by gravity sedimentation. However, the FCDs have a similar density to human plasma protein, suggesting that the protein-FCDs cannot be separated from free protein or FCDs by gravity. Therefore, the BCA method was modified based on the principle that FCDs could react specifically with the BCA reagent and the absorbance of the BCA-FCDs was proportional to the concentration (Figure 10a,b). The excess FCDs in the reaction system were separated through $50 \mathrm{kDa}$ ultrafiltration centrifuge tubes to determine the concentration of FCDs adsorbed by plasma proteins. Since both FCDs and proteins could react with BCA reagents, Bradford reagent was used to check 
the ultrafiltrate to ensure that there was no protein mixing before proceeding to the next step. The results showed that three types of proteins adsorbed high levels of FCDs within $5 \mathrm{~min}$, and the adsorption within $4 \mathrm{~h}$ did not significantly change (Figure 10c). Increasing the concentration of FCDs did not increase the adsorption level, indicating that the tested human plasma proteins and FCDs had reached saturated adsorption. The adsorption situation within $5 \mathrm{~min}$ was further studied, and it was found that the adsorption of the three types of proteins reached high levels within $0.5 \mathrm{~min}$ (Figure 10d). This proved that the interaction between proteins and FCDs happened rapidly, which was probably completed less than $0.5 \mathrm{~min}$ that was not detectable using the current method. The interaction between FCDs and protein was stable. Zhang et al. monitored the evolution of the reaction system from $5 \mathrm{~min}$ to $5 \mathrm{~h}$, and no time-dependent change in protein binding was found [53]. The protein adsorption behavior was likely to reach equilibrium within $5 \mathrm{~min}$. Tenzer et al. reported that $\mathrm{SiO}_{2}$ nanoparticles incubated in human plasma adsorbed more than 300 proteins in a short period $(<0.5 \mathrm{~min})$ [54]. Dell'Orco et al. established a mathematical model to describe the kinetic process of protein corona formation based on the association/dissociation rate and also demonstrated protein corona could be formed quickly in a very short time $(t=0.05 \mathrm{~s})$, and the complex was relatively stable within the first $20 \mathrm{~s}$ [55]. Interestingly, it was also found that the concentration of FCDs adsorbed by the same amount of protein increased with the increase of theoretical molecular weight of the protein (HSA: $66 \mathrm{kDa}$; HGG: $180 \mathrm{kDa}$; HF: $240 \mathrm{kDa}$ ), the adsorption capacity was sorted as HF > HGG > HSA, which fully demonstrated that the ability of proteins to combine with FCDs depends on the intrinsic properties of proteins.
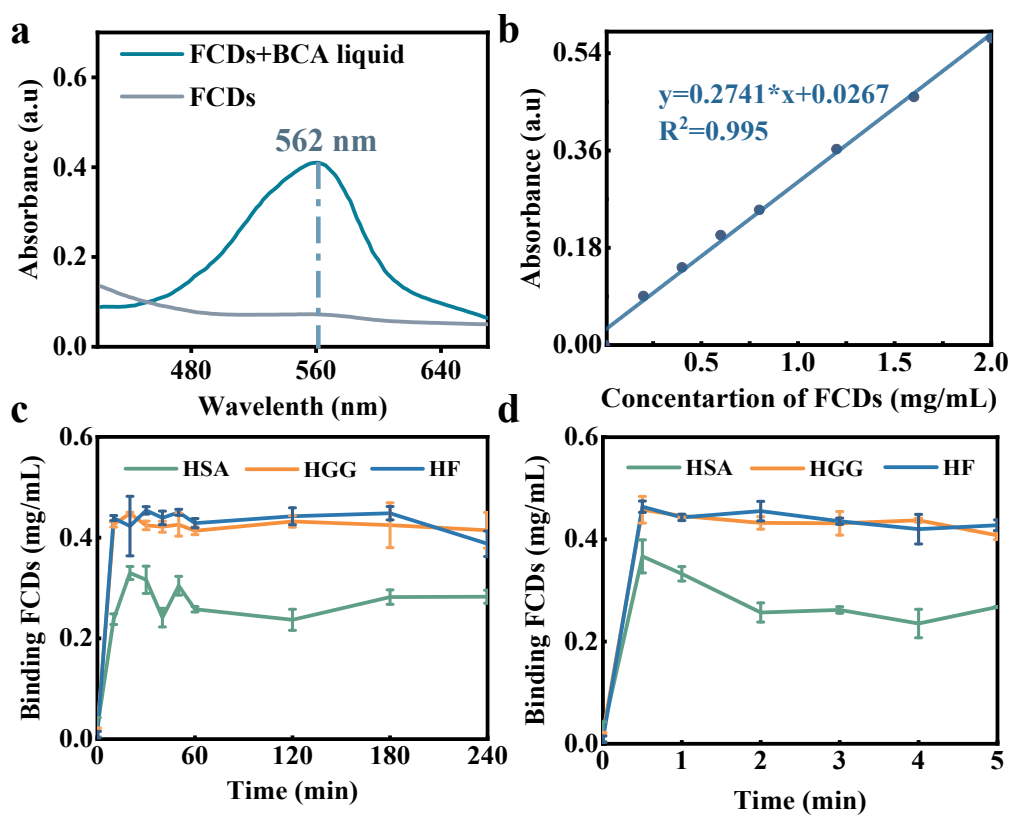

Figure 10. Adsorption capacity experiment of FCDs with HSA, HGG and HF. (a) UV-Vis absorption spectra of FCDs and BCA reagents. (b) Standard curve of FCDs concentration and absorbance at the ultraviolet wavelength of $562 \mathrm{~nm}$. Binding amount of FCDs by HSA, HGG and HF from (c) 0-240 min and (d) 0-5 $\mathrm{min}$.

\section{Conclusions}

The FCDs derived from grilled Spanish mackerel could affect the size, stability and aggregation morphology of HSA, HGG, and HF, resulting in significantly different surface potential changes. The interaction between FCDs and HSA, HGG, and HF changed the secondary structure of the three types of proteins. The FCDs bound to HSA, HGG, and HF through the static mechanism, and the adsorption reaction occurred quickly within $0.5 \mathrm{~min}$. The binding affinity of the FCDs to the plasma proteins was sorted as follows: HF $>$ HGG > HSA. The interaction between FCDs and three types of plasma proteins 
remains to be further explored to demonstrate the effect on cell uptake, cytotoxicity and cell metabolism.

Author Contributions: Conceptualization, G.C. and M.T.; methodology, Y.S. and K.L.; validation, Y.S. and M.T.; investigation, G.C.; writing—original draft preparation, G.C.; writing—review and editing, M.T.; funding acquisition, M.T. All authors have read and agreed to the published version of the manuscript.

Funding: This research was funded by the National Nature Science Foundation of China (31872915) and Liaoning Province Education Administration (J2020102).

Data Availability Statement: The datasets generated for this study are available on request to the corresponding author.

Conflicts of Interest: The authors declare no conflict of interest.

\section{References}

1. Wang, H.; Su, W.; Tan, M. Endogenous fluorescence carbon dots derived from food items. Innovation 2020, 1, 100009. [CrossRef]

2. Hillyer, J.F.; Albrecht, R.M. Gastrointestinal persorption and tissue distribution of differently sized colloidal gold nanoparticles. J. Pharm. Sci. 2001, 90, 1927-1936. [CrossRef]

3. Cedervall, T.; Lynch, I.; Lindman, S.; Berggård, T.; Thulin, E.; Nilsson, H.; Dawson, K.A.; Linse, S. Understanding the nanoparticleprotein corona using methods to quantify exchange rates and affinities of proteins for nanoparticles. Proc. Natl. Acad. Sci. USA 2007, 104, 2050-2055. [CrossRef]

4. Nel, A.E.; Mädler, L.; Velegol, D.; Xia, T.; Hoek, E.M.; Somasundaran, P.; Klaessig, F.; Castranova, V.; Thompson, M. Understanding biophysicochemical interactions at the nano-bio interface. Nat. Mater. 2009, 8, 543-557. [CrossRef] [PubMed]

5. Song, Y.; Wu, Y.; Wang, H.; Liu, S.; Song, L.; Li, S.; Tan, M. Carbon quantum dots from roasted Atlantic salmon (Salmo salar L.): Formation, biodistribution and cytotoxicity. Food Chem. 2019, 293, 387-395. [CrossRef] [PubMed]

6. Cong, S.; Liu, K.; Qiao, F.; Song, Y.; Tan, M. Biocompatible fluorescent carbon dots derived from roast duck for in vitro cellular and in vivo C. elegans bio-imaging. Methods 2019, 168, 76-83. [CrossRef] [PubMed]

7. Song, Y.; Wang, H.; Zhang, L.; Lai, B.; Liu, K.; Tan, M. Protein corona formation of human serum albumin with carbon quantum dots from roast salmon. Food Funct. 2020, 11, 2358-2367. [CrossRef] [PubMed]

8. Liu, K.; Song, Y.; Tan, M. Toxicity alleviation of carbon dots from roast beef after forming protein coronas with human serum albumin. J. Agric. Food Chem. 2020, 68, 9789-9795. [CrossRef]

9. Nanjappa, V.; Thomas, J.K.; Marimuthu, A.; Muthusamy, B.; Radhakrishnan, A.; Sharma, R.; Khan, A.A.; Balakrishnan, L.; Sahasrabuddhe, N.A.; Kumar, S.; et al. Plasma Proteome Database as a resource for proteomics research: 2014 update. Nucleic Acids Res. 2013, 42, D959-D965. [CrossRef]

10. Nair, M. The Circulatory System. Fundamentals of Anatomy and Physiology for Student Nurses, 2nd ed.; Wiley-Blackwell: Chichester, $\mathrm{UK}, 2016$.

11. Wimuktiwan, P.; Shiowatana, J.; Siripinyanond, A. Investigation of silver nanoparticles and plasma protein association using flow field-flow fractionation coupled with inductively coupled plasma mass spectrometry (FIFFF-ICP-MS). J. Anal. At. Spectrom. 2015, 30, 245-253. [CrossRef]

12. Busher, J.T. Serum albumin and globulin. In Clinical Methods: The History, Physical, and Laboratory Examinations; Butterworth: Boston, MA, USA, 1990; Volume 3, pp. 497-499.

13. Melillo, A. Applications of serum protein electrophoresis in exotic pet medicine. Vet. Clin. N. Am. Exot. Anim. Pract. 2013, 16, 211-225. [CrossRef] [PubMed]

14. Imbach, P. Immune thrombocytopenic purpura and intravenous immunoglobulin. Cancer 1991, 68, 1422-1425. [CrossRef]

15. Samuelsson, A.; Towers, T.L.; Ravetch, J.V. Anti-inflammatory activity of IVIG mediated through the inhibitory Fc receptor. Science 2001, 291, 484-486. [CrossRef]

16. Herrick, S.; Blanc-Brude, O.; Gray, A.; Laurent, G. Fibrinogen. Int. J. Biochem. Cell Biol. 1999, 31, 741-746. [CrossRef]

17. Zhdanova, N.; Shirshin, E.A.; Maksimov, E.; Panchishin, I.M.; Saletsky, A.M.; Fadeev, V.V. Tyrosine fluorescence probing of the surfactant-induced conformational changes of albumin. Photochem. Photobiol. Sci. 2015, 14, 897-908. [CrossRef]

18. Cong, S.; Bi, J.; Song, X.; Yu, C.; Tan, M. Ultrasmall fluorescent nanoparticles derived from roast duck: Their physicochemical characteristics and interaction with human serum albumin. Food Funct. 2018, 9, 2490-2495. [CrossRef]

19. Liu, R.; Liu, K.; Tan, M. Nanocorona formation between foodborne nanoparticles extracted from roast squid and human serum albumin. J. Agric. Food Chem. 2019, 67, 10470-10480. [CrossRef]

20. Carter, D.C.; He, X.M.; Munson, S.; Twigg, P.D.; Gernert, K.M.; Broom, M.B.; Miller, T.Y. Three-dimensional structure of human serum albumin. Science 1989, 244, 1195-1198. [CrossRef]

21. Sugio, S.; Kashima, A.; Mochizuki, S.; Noda, M.; Kobayashi, K. Crystal structure of human serum albumin at $2.5 \AA ̊$ resolution. Protein Eng. Des. Sel. 1999, 12, 439-446. [CrossRef] [PubMed]

22. He, X.M.; Carter, D.C. Atomic structure and chemistry of human serum albumin. Nature 1992, 358, 209-215. [CrossRef] [PubMed] 
23. Kumakura, M.; Yoshida, M.; Asano, M. Adsorption of $\gamma$-globulin on polymer surfaces having various chemical and physical structures. J. Appl. Polym. Sci. 1990, 41, 177-184. [CrossRef]

24. Finlayson, J.S.; Mosesson, M.W. Heterogeneity of human fibrinogen. Biochemistry 1963, 2, 42-46. [CrossRef]

25. Mosesson, M.; Finlayson, J.; Umfleet, R. Human fibrinogen heterogeneities: III. Identification of $\gamma$ chain variants. J. Biol. Chem. 1972, 247, 5223-5227. [CrossRef]

26. Mosesson, M. Fibrinogen structure and fibrin clot assembly. Semin. Thromb. Hemost. 1998, 24, 169-174. [CrossRef] [PubMed]

27. Scheraga, H.A. The thrombin-fibrinogen interaction. Biophys. Chem. 2004, 112, 117-130. [CrossRef] [PubMed]

28. Mosesson, M.W. Fibrinogen and fibrin structure and functions. J. Thromb. Haemost. 2005, 3, 1894-1904. [CrossRef] [PubMed]

29. Weisel, J.W. Fibrinogen and fibrin. Adv. Protein Chem. 2005, 70, 247-299.

30. Krakow, W.; Endres, G.; Siegbl, B.; Schekaga, H. An electron microscopic investigation of the polymerization of bovine fibrin monomer. J. Mol. Biol. 1972, 71, 95-103. [CrossRef]

31. Bhattacharjee, S. DLS and zeta potential-What they are and what they are not? J. Control. Release 2016, 235, 337-351. [CrossRef]

32. Il'Ichev, Y.V.; Perry, A.J.L.; Simon, J.D. Interaction of ochratoxin a with human serum albumin. Preferential binding of the dianion and Ph effects. J. Phys. Chem. B 2001, 106, 452-459. [CrossRef]

33. Li, X.; Wang, S. Study on the interaction of (+)-catechin with human serum albumin using isothermal titration calorimetry and spectroscopic techniques. New J. Chem. 2015, 39, 386-395. [CrossRef]

34. Eftink, M.R.; Ghiron, C.A. Fluorescence quenching studies with proteins. Anal. Biochem. 1981, 114, 199-227. [CrossRef]

35. Parham, H.; Saeed, S. Resonance Rayleigh scattering method for determination of ethion using silver nanoparticles as probe. Talanta 2015, 131, 570-576. [CrossRef]

36. Lakowicz, J.R.; Masters, B.R. Principles of fluorescence spectroscopy, third edition. J. Biomed. Opt. 2008, 13, 029901. [CrossRef]

37. Peng, X.; Wang, X.; Qi, W.; Su, R.; He, Z. Affinity of rosmarinic acid to human serum albumin and its effect on protein con-formation stability. Food Chem. 2016, 192, 178-187. [CrossRef] [PubMed]

38. Chi, Z.; Liu, R.; Zhang, H. Potential enzyme toxicity of oxytetracycline to catalase. Sci. Total Environ. 2010, 408, 5399-5404. [CrossRef] [PubMed]

39. Wang, Y.; Sun, Y.; Yang, J.; Dai, L.; Ji, N.; Xiong, L.; Sun, Q. Interactions of surface-functionalized starch nanoparticles with pepsin and trypsin in simulated gastrointestinal fluids. J. Agric. Food Chem. 2020, 68, 10174-10183. [CrossRef]

40. Makarska-Bialokoz, M. Interactions of hemin with bovine serum albumin and human hemoglobin: A fluorescence quenching study. Spectrochim. Acta Part A Mol. Biomol. Spectrosc. 2018, 193, 23-32. [CrossRef]

41. Yan, F.; Zou, Y.; Wang, M.; Mu, X.; Yang, N.; Chen, L. Highly photoluminescent carbon dots-based fluorescent chemosensors for sensitive and selective detection of mercury ions and application of imaging in living cells. Sens. Actuators B Chem. 2014, 192, 488-495. [CrossRef]

42. Zhang, G.; Wang, L.; Pan, J. Probing the binding of the flavonoid diosmetin to human serum albumin by multispectroscopic techniques. J. Agric. Food Chem. 2012, 60, 2721-2729. [CrossRef]

43. Zhao, X.; Hao, F.; Lu, D.; Liu, W.; Zhou, Q.; Jiang, G. Influence of the surface functional group density on the car-bon-nanotubeinduced $\alpha$-chymotrypsin structure and activity alterations. ACS Appl. Mater. Interf. 2015, 7, 18880-18890. [CrossRef]

44. Arakawa, H.; Umemura, K.; Ikai, A. Protein images obtained by STM, AFM and TEM. Nature 1992, 358, 171-173. [CrossRef]

45. Kiselev, M.A.; Gryzunov, I.A.; Dobretsov, G.E.; Komarova, M.N. Size of a human serum albumin molecule in solution. Biofizika 2001, 46, 423-427. [PubMed]

46. Arwin, H. Optical properties of thin layers of bovine serum albumin, $\gamma$-globulin, and hemoglobin. Appl. Spectrosc. 1986, 40, 313-318. [CrossRef]

47. Bae, Y.M.; Oh, B.-K.; Lee, W.; Lee, W.H.; Choi, J.-W. Study on orientation of immunoglobulin G on protein G layer. Biosens. Bioelectron. 2005, 21, 103-110. [CrossRef]

48. Fuss, C.; Palmaz, J.C.; Sprague, E.A. Fibrinogen: Structure, function, and surface interactions. J. Vasc. Interv. Radiol. 2001, 12, 677-682. [CrossRef]

49. Marchin, K.L.; Berrie, C.L. Conformational changes in the plasma protein fibrinogen upon adsorption to graphite and mica investigated by atomic force microscopy. Langmuir 2003, 19, 9883-9888. [CrossRef]

50. Evans-Nguyen, K.M.; Fuierer, R.R.; Fitchett, B.D.; Tolles, L.R.; Conboy, J.C.; Schoenfisch, M.H. Changes in adsorbed fibrinogen upon conversion to fibrin. Langmuir 2006, 22, 5115-5121. [CrossRef]

51. Kollman, J.M.; Pandi, L.; Sawaya, M.R.; Riley, M.; Doolittle, R.F. Crystal structure of human fibrinogen. Biochemistry 2009, 48, 3877-3886. [CrossRef]

52. Fowler, W.E.; Erickson, H.P. Trinodular structure of fibrinogen: Confirmation by both shadowing and negative stain electron microscopy. J. Mol. Biol. 1979, 134, 241-249. [CrossRef]

53. Zhang, H.; Burnum-Johnson, K.; Luna, M.L.; Petritis, B.O.; Kim, J.-S.; Qian, W.-J.; Moore, R.J.; Heredia-Langner, A.; Webb-Robertson, B.-J.; Thrall, B.D.; et al. Quantitative proteomics analysis of adsorbed plasma proteins classifies nanoparticles with different surface properties and size. Proteomics 2011, 11, 4569-4577. [CrossRef] [PubMed] 
54. Tenzer, S.; Docter, D.; Kuharev, J.; Musyanovych, A.; Fetz, V.; Hecht, R.; Schlenk, F.; Fischer, D.; Kiouptsi, K.; Reinhardt, C.; et al. Rapid formation of plasma protein corona critically affects nanoparticle pathophysiology. Nat. Nanotechnol. 2013, 8, 772-781. [CrossRef] [PubMed]

55. Dell'Orco, D.; Lundqvist, M.; Oslakovic, C.; Cedervall, T.; Linse, S. Modeling the time evolution of the nanoparticle-protein corona in a body fluid. PLoS ONE 2010, 5, e10949. [CrossRef] [PubMed] 